\title{
Mobile Computing as a Game Changer in Kingdom of Saudi Arabia Industries
}

\author{
Aasim Zafar \\ Assistant Professor, \\ Department of Information Systems, \\ Faculty of Computing and Information Technology, \\ King Abdulaziz University, Jeddah \\ Kingdom of Saudi Arabia \\ Walaa Alhabashi \\ Department of Information Systems, \\ Faculty of Computing and Information Technology, \\ King Abdulaziz University, Jeddah \\ Kingdom of Saudi Arabia
}

\author{
Amjad Almubark \\ Department of Information Systems, \\ Faculty of Computing and Information Technology, \\ King Abdulaziz University, Jeddah \\ Kingdom of Saudi Arabia \\ Bashaier Alwagdany \\ Department of Information Systems, \\ Faculty of Computing and Information Technology, \\ King Abdulaziz University, Jeddah \\ Kingdom of Saudi Arabia
}

\author{
Awatif Hashbal Ali \\ Department of Information Systems, \\ Faculty of Computing and Information Technology, \\ King Abdulaziz University, Jeddah \\ Kingdom of Saudi Arabia
}

\begin{abstract}
Today, mobile computing has permeated the globe in both business and social culture. Mobile computing includes a number of technologies and devices, such as wireless LANs, smart phones, notebook computers, Personal Digital Assistant (PDA) and others which enable people to access, store, process, create and communicate information anywhere and anytime.

In recent years, the different mobile computing technologies and devices widely introduced to the Kingdom of Saudi Arabia (KSA). It has changed the complete landscape of human being life during time and it results technological changes and societal changes which exert pressure on business and government environment in KSA.
\end{abstract}

The Mobile computing technologies have significant influence on the Saudi government and private industries and also facilitate a lot of transactions and procedures in all fields. This paper attempts to describe the affect and impact of mobile computing on government and private industries of Saudi Arabia.

\section{Keywords}

Mobile computing, Mobile devices, Mobile technologies, Saudi Arabia industries

\section{INTRODUCTION}

Mobile computing devices and technologies are rapidly growing and have gained popularity in organizations in the last few years in Kingdom of Saudi Arabia (KSA). The widespread of mobile computing in the world has motivated Saudi government institutions and private businesses to provide different online services and also provide many applications that can be used in smart phones [1].
Today users are able to install applications on their mobile devices which facilitate access to information, surf the internet, update documents, support video and voice conferencing and send and receive e-mail stream video files anytime/anywhere. The appearance of mobile computing technologies and devices in KSA make a lot of changes in technique and social environment and it help organizations to find solution to the their business problem and make the life more easiest [2].

In our research we will discuss the growth, challenges, success and limitations of mobile computing in KSA. Also, we will try to cover some applications of mobile computing and talk about specific areas that take benefits from these applications. In addition, we will see how the changes in technique and social environment affect government and business industries in KSA.

\section{RELATED WORK}

In this section, we will discuss some works attempted to employ mobile computing technologies in government institutes and private companies, and its effect on productivity and improve reliability. Mobile computing has verified the maximum benefit in enterprise computing, it gain significant advantage in transforming and using huge information and communication technologies to change the nature of enterprise computing [21]. The private companies like banks that use mobile computing have significant effects on the market, the widespread uses of smart phones have increased the demand for m-banking services to reach and satisfies the consumer regard the existent services [23]. But the biggest problems facing mobile computing at enterprise lies in enterprise-level scaling in a strongly connected data mass [24]. On the other hand it was observed that at enterprise level the employee who uses enterprise mobile application (EMA) 
in their workplace has increased the productivity and the creativity at job performance of both the habitual use and task technology fit for enterprise mobile application [25].

Sunghun Chung (2015) examine how the employees improve their perceived job performance with using Mobile Enterprise Systems (MES), and tests the regular role of task characteristics on the relationship between MES usage and perceived job performance, by conducted a large-scale survey based on the extant technology acceptance model (TAM) among the employees who use MES in their workplace. The findings suggest that both positive attitude toward MES and a high level of habitual MES usage are positively associated with perceived job performance [24].

Khairy Assar (2015) discussed the existent status of information and communication technology in Kingdom of Saudi Arabia to move from electronic government to mobile government services and reviewed the M-government implementation in KSA. He focused on all the possible barriers and drivers of M-government in Saudi Arabia government. His pilot study can be a guide for the effective executing of M-government in KSA [26].

Here in this paper, we have tried to explain how mobile computing has changed the way business is done in kingdom of Saudi Arabia, and its impact in KSA industries at both government and privet sectors. Also, it discusses the derived value from mobile computing in KSA businesses and industries.

\section{THE GROWTH OF MOBILE COMPUTING}

The emergence of mobile computing has become a significant feature in many countries. The statistical numbers shows the widespread growing of smart phones usage by consumers in Saudi Arabia. Many studies have shown that the number of smart devices exceeded 53 million in a short time. The enormous evolution of smart devices has encouraged different organizations in Saudi Arabia to deliver high quality online services. This has led Saudi people to exploit this advantage and download different applications at their devices and use it to accomplish their work at anytime [3].

The continuous growth of mobile computing and its advances, the development of wireless communications, and the widespread adoption of mobile devices with the advantage of low-cost applications that work on different smart devices have substantially improved the mobile computing evolution. Possession of smart devices become a personal feature to many users in the world, if we notice that mobile phones are becoming the controller basis for many activity of our daily live such as communicating with different people, accessing data, learning, online shopping, entertainment and socialization. There are some other uses of mobile networks and its applications. One example is mobile payments and transactions through using mobile phones and micro financing services. Mobile technology is become the main concern from businesses and their owners, they understand its value and untapped possibility, further more the organizations today are using short message services and mobile computing networks to interact with employees against government instructions and requests [4].

The evolution of smart phones and tablets that have the capability to run adapted desktop operating systems, has enabled the owners to interact and manipulate the world's information at their' fingertips, and as a result this has already changed the ways in which users act in their enterprise, how they act in their own daily lives, and there society in general. Nowadays employees tend to bring their private mobile devices to work, this leads them to reach IT management, for support and security. Mobile computing has change the way that users spend specific time to work and complete their daily tasks and handle additional work requests, and how do they quickly accomplish and fulfillment they business policies [5].

\section{MOBILE COMPUTING TECHNOLOGY APPLICATIONS}

There are many services and applications that mobile computing technologies can provide which are needed by all organizations and people regardless of the fact they are mobile or not [8]. Mobile computing applications provide secure, instant and anytime, anywhere access to data and information. Mobile computing applications is one of the critical factors for the success of any organization in order to serve customers better and to enhance the certainty of business success [9]. Generally, there are two categories of mobile computing applications: vertical and horizontal.

\subsection{Horizontal application}

Today, there are a number of horizontal mobile computing applications which are very popular among end users, large and small organizations. Horizontal applications have wide spread distribution and include software that provides functions such as: presentation, scheduling, browsing, word processing and email. These types of applications generally become standard on laptops and Palmtops with operating system such as Windows 2007 [2].

\subsection{Vertical application}

A vertical application is application that only related to a specific business process and targets a smaller number of end users with specific skills within an organization. Vertical applications are usually used in industries e.g. shipping, utilities, medical, warehousing and public safety. Enterprise resource planning (ERP) and customer relationship management (CPM) are two examples of vertical application [2].

Vertical applications are more complicated to use than horizontal applications because they need to join with other systems used in the organization, also they may require information technologies (IT) assistance.

\section{AFFECT OF MOBILE COMPUTING ON THE GOVERNMENT AND BUSINESS INDUSTRIES IN KSA}

Mobile computing and the new technologies of mobile devices have affected on governments and private industries through supporting the productivity and creativity of employees. Recent researches shift attention to the role of mobile computing and the impact on the employees in the workplace. Most enterprises now depend on mobile technologies with a significant role to increase their operational efficiency, improve the interaction between employees and customers [24]. New mobile computing technologies in KSA today exert a significant impact on individuals, government organizations and private businesses. The mobile computing has an effect on a multitude of fields such as: healthcare, skills and education, army, government and private business, business and ministries [13]. The world's dependence on mobile computing encouraged Saudi business and government institutions to enhance online services, through the use of smart phones and different applications [14]. 


\subsection{Private business industries in KSA}

The business field takes the benefits from rapidly growing of mobile computing applications as any other field in KSA. Many traders and suppliers think about how to make money from these rapidly expanding technologies, devices and applications.

Today, using mobile computing applications in different devices e.g. tablet computers and smart phones in KSA help to access business information from any location and any in time, access to different business applications, access to suppliers and partners from anywhere and improve communications with save time. In addition, there are other benefits taken from using the latest version of applications like the ability to reduce capital expenses, the ability to improve customer sales and service from any location and increases in flexibility and adaptability.

For example, Saudi Airlines Company has affected through the mobile computing that issued application for smart devices the customer can search for flights, make reservations and other services in any location and any time. This application supported the company by facilitating for users to get access to the main system of the company [20].

\subsection{Government industries in KSA}

In government industries, mobile computing provides different public services electronically through the eGovernment [6]. Educational institutions move toward electronic learning and mobile learning. Also, mobile computing provides healthcare and clinical services through E-systems and mobile applications. Mobile Government applications became a part of the e-government implementations [7]. This section will focus on the affects of mobile computing on three fields of government industries in KSA which are healthcare, education and security.

\subsection{1 in healthcare field}

The improvements and advancements in mobile computing in Kingdom of Saudi Arabia have an important affect to improve healthcare delivery, enhance health protection services to be more appropriate to the patients, rise the overall effectiveness and efficiency of health care staffs and reduce health care costs. In recent years, there are different mobile computing applications and wireless technologies in KSA which allow healthcare staffs to supervise patients remotely, and provide them with healthcare advises, support and mention them in suitable time [10].

For example, King Khalid Eye Specialist Hospital (KKESH) is one of the most leading hospitals in the field of ophthalmology managed by the Ministry of Health (MOH) of the Kingdom of Saudi Arabia. KKESH selects InterSystemsTrakCare application with the help of mobile computing devices to ensure privilege in healthcare field. InterSystemsTrakCare is an internet-based unified healthcare that speedily transfers the interests of an electronic patient record and it is widely used database system in different clinical applications. InterSystemsTrakCare will help KKESH to collect all of their patients' information, both clinical and non-clinical, in a single electronic medical record. Only authorized clinicians can access the information securely at anywhere and anytime by using any of the mobile computing devices, including smart phones and tablets. Also in KKESH the patients can easily use their cell phones, tablets or any personal computing device to make their appointments, view and print patient appointment, refill medication form and other electronic services.

\subsection{2 in education field}

The introduction of mobile computing technologies and applications to education field in the KSA facilitate a lot of things in education. Over the last 20 years, the use of mobile computing in education fields has become more and more widespread. The computers devices grew increasingly affordable for schools and universities, and there were many number of educational institutions established computer labs with wireless technologies and allow students to use these labs and do their work [12].

In recent years, many instructors use smart-boards in their classroom lectures and allowing them to access to more electronic resources and applications in order to enhance the educational experiences and capture the students' attention which help them to increase their chances of understanding educational material taught by instructors. Now, tablet computers and other mobile computing tools with many applications are easier for schools and institutions of higher learning. It helps students to routinely inserted into educational environments and absorb classroom lessons and remember all information taught to them by instructors. Mobile phones applications today enables students and instructors to easily collect, save, and record information from many fields for educational purposes and bring new opportunities of learning.

For example, King Abdul-Aziz University has implemented blackboard system as a learning management system that allows different ways of communication between students and teachers through virtual classroom, discussion board, announcement and more. It provides online activities such as quizzes, exams and assignments. With mobile computing, they can access to the system from anywhere and at any time through the Blackboard Mobile Learn application that are available in most of the smart phones and tablets.

\subsubsection{Traffic Systems}

The mobile computing technologies have created an opportunity for mobile computing and online traffic simulations. In recent, the data processing and traffic simulation are performed in a distributed fashion by mobile computing and by using different mobile computing devices like smart phones and tablets.

For example, the mobile computing in Saudi Arabia has contributed to facilitate customer access to the information requested. In government, "Saher" is a system of the Ministry of Interior, which used to follow traffic violations through an application that installed on smart phones with using identification number to search for traffic violations with clarifying its time and place. This application can be developed in the future so that the customer can pay the amount of money for these traffic violations through the application linking of Saudi banks, and thus have contributed to the reduction of effort and waste of time [19]

\section{DERIVED VALUE FROM MOBILE COMPUTING IN KSA INDUSTRIES}

Many of mobile computing technologies, devices, and applications contributed dramatically in different fields in KSA like education, healthcare, business, government services, ministries, banks and financial services, authorities, transportation industry. These improvements of mobile computing in KSA give competitive advantage with developed countries. Mobile computing helps employees and citizens to do their daily work in anywhere and in anytime with low cost and efforts. The introduction of mobile 
computing in KSA industries solve many complicated problems and provides an easy way to increase efficiency, profitability and productivity.

Mobile computing in KSA enables people and organization to easily access information anywhere and anytime which eliminate delay operations, fewer complaints, improve customer service with greater accuracy and reduce the number of required intermediate support staff.

Mobile computing technologies in KSA improve efficiency of government organizations and business services that combine the technologies into their fixed information systems. Mobile computing can develop efficiency in many ways like enabling business process reengineering, saving time, reducing rework, reducing unnecessary travel and improving accuracy.

Mobile computing technologies can enhance management effectiveness by developing information flow, information quality, and ability to control a mobile workforce. It also improves the ability to manage different operations.

\section{CONCLUSION}

Mobile computing is the ability to use technologies and devices to create, access, process, store and communicate information wirelessly and it is a rapidly growing market. With mobile computing devices and applications, different government institutions and private organizations in KSA can solve their problems and work more efficiency and people can work from the comfort of any location they wish and any time.

Nowadays, Mobile computing technologies has not only changed the ways that the business communicate, store and access information, it has reshaped the business models of some of the leading tech business and government industries in KSA. As we write, mobile computing technology can improve the efficiency of government industries as well as private business services by saving time, reducing rework, reducing unnecessary travel and improving accuracy.

\section{REFERENCES}

[1] Helal, Abdelsalam A. "Any Time, Anywhere Computing: Mobile Computing Concepts and Technology", 1999. Hingham, MA, USA: Kluwer Academic Publishers, Copyright (C) 1999. Kluwer Academic Publishers.

[2] Devashish Goswami. " Mobile Computing", 2013. International Journal of Advanced Research in Computer Science and Software Engineering, pp. 846-855. Research Paper Available online at:

[3] Mutlaq B. Alotaibi. "Mobile Computing Trends in Saudi Arabia: An Exploratory Study" 2015, I.J. Information Technology and Computer Science, 01, 21-32

[4] Bojanova, Irena; Chang, J.Morris; Chou, Wes; Murugesan, San, "The New Mobile Computing Landscape", 2012. IT Professional , vol.14, no.5, pp. 9,11 .

[5] Fischer, N.; Smolnik, S., "The Impact of Mobile Computing on Individuals, Organizations, and Society Synthesis of Existing Literature and Directions for Future Research", 2013. System Sciences (HICSS), Hawaii International Conference on, pp.1082,1091, 7-10.

[6] Ministry of Communications and Information Technology. "Information and Telecommunication Technology in Saudi Arabia". White Paper
[7] Abanumy A, Mayhew P. "M-government Implications For E-Government In Developing Countries: The Case Of Saudi Arabia". Available online at: http://workspace.unpan.org/sites/internet/Documents/UN PAN033540.pdf

[8] Asoke. K Talukder, Roopa R. Yavagal, Asoke K. Talukder ."Mobile Computing Technologies, applications and services creation", 2005. Tata McGrawHill Publishing Company Limited ,Ninth Reprint 2008.

[9] M. Vijay Kumar, "Mobile Computing Applications". Sankhya Infotech Limited, mobile.tsm@ @ankhya.net

[10] Darshan Modani \& Seif Eldrasi , "Mobile Computing in Healthcare Needs, Applications, Issues and Future Trends" ,University of Houston ,Department of Computer Science, Houston TX USA.

[11] Siddiqi, A.A. ; Ahmed, M. ; Alginahi, Y.M. ; Alharby, A. "Use of information and mobile computing technologies in healthcare facilities of Saudi Arabia", 2009.

[12] Guido Roßling, Henning Bar, Christoph Trompler and Chin-Man Choi. "Mobile Computing in Education", 2003. Department of Computer Science Darmstadt University of Technology, Germany.

[13] O. D. E. Papers, "Cloud Computing: The Concept, Impacts and the Role of Government Policy," OECD Publishing., 2014.

[14] CITC, 2012. [Online].

[15] M. Satyanarayanan, "Mobile Computing: the Next Decade," 2013

[16] N. Ramamurthy, "Role of mobile agents in mobile computing environment".

[17] C. Robb, ""Security at the Edge - Protecting Mobile Computing Devices," JULY 2009.

[18] S. S. Nikolaus Fischer, "The Impact of Mobile Computing on Individuals, Organizations, and Society Synthesis of Existing Literature and Directions for Future," in Hawaii International Conference on System Sciences, Hawaii .

[19] M. O. Interior, "http://www.moi.gov.sa," 2014. [Online].

[20] S. Airlines, "http://www.saudiairlines.com/portal/ saudiairlines/Welcome," 2014. [Online].

[21] J. Lee, "The future of enterprise computing," in Computer and Information Science (ICIS), 2013.

[22] K. H. S.Aijaz A., "Mobile banking adoption: A literature review," 2015.

[23] A. W. E.James, " NEXT-GENERATION MOBILE COMPUTING," 2014

[24] L. ,. K. Y. C. J. C.Sunghun, "Exploring digital creativity in the workspace: The role of enterprise mobile applications on perceived job performance and creativity," 2015

[25] L.,. K. Y. K. K. C.Sunghun, "Job Performance through mobile enterprise systems: The Role of organizational agility, location independence, and task characteristics" 2014.

[26] Assar, "M-government in Saudi Arabia", Computer Science and Software Engineering, January 2015. 